Manuscript for Review

\title{
Quad configuration for improved thermal design of a cascode current mirror
}

\begin{tabular}{|c|c|}
\hline Journal: & Electronics Letters \\
\hline Manuscript ID: & ELL-2011-2955.R1 \\
\hline Manuscript Type: & Letter \\
\hline Date Submitted by the Author: & 20-Nov-2011 \\
\hline Complete List of Authors: & $\begin{array}{l}\text { Jablonski, Michal; Ghent University, ELIS } \\
\text { De Mey, Gilbert; Ghent University, ELIS } \\
\text { Kos, Andrzej; AGH University of Science and Technology, Institute of } \\
\text { Electronics }\end{array}$ \\
\hline Keywords: & $\begin{array}{l}\text { ANALOGUE INTEGRATED CIRCUITS, CIRCUIT LAYOUT, CIRCUIT } \\
\text { OPTIMISATION, THERMAL ANALYSIS, MOSFET }\end{array}$ \\
\hline \multicolumn{2}{|c|}{$\begin{array}{l}\text { Note: The following files were submitted by the author for peer review, but cannot be converted to } \\
\text { PDF. You must view these files (e.g. movies) online. }\end{array}$} \\
\hline $\begin{array}{l}\text { EL_QCM.tex } \\
\text { EL_QCM.bbl.tex } \\
\text { IEEEtran.cls }\end{array}$ & \\
\hline
\end{tabular}




\title{
Quad configuration for improved thermal design of a cascode current mirror
}

\author{
M. Jabłoński, G. De Mey and A. Kos
}

\begin{abstract}
In this paper, the influence of a temperature gradient on the performance of a current mirror will be investigated. It will be proved that a new design based on a quad layout can make the current mirror almost insensitive to a temperature gradient.
\end{abstract}

\section{INTRODUCTION}

A current mirror is on the one hand based on the fact that the transistors should have identical characteristics and on the other hand their output characteristic should be horizontal in order to provide constant current. As a consequence the transistors should also have the same temperature. Any temperature difference will inevitably give rise to non matching characteristics and a non proper operating current mirror. Just one report could be found related to this problem [1].

A cascode current mirror layout (fig. 1(a)) is often used for its high output impedance [2][3]. It will be proved by numerical simulation and also theoretically that a temperature change of either transistor 1 or 2 has a much higher influence on the output current than a similar temperature variation of transistor 3 or 4 .

If the temperatures of all transistors are changed equally, their characteristic remain identical and there will be no influence on the circuit performance. A problem arises if a temperature distribution is created due to other heat dissipating transistors on the same chip. A temperature gradient is then built up across the current mirror. The temperature differences will then cause a malfunctioning of the circuit especially when the transistors 1 or 2 have different temperatures. A solution to this problem will be proposed. Both transistors 1 and 2 have to be split in two equal ones in parallel and the resulting four have to be placed geometrically in a so called quad layout. It will be shown by numerical simulation and theoretically that this configuration is almost insensitive to any temperature gradient. 


\section{NUmERICAL SIMULATION OF the CASCODE LAYOUT}

The numerical simulations have been carried out using the software package TI-TINA made availaible by Texas Instruments [5]. It is a Spice like program but it allows to give every component a different temperature. Simulations have been carried out for an input current $I_{\text {in }}=500 \mu \mathrm{A}$ and 4 identical, N-Type, wide channel, MOSFET transistor models (SPICE level-2) with W/L $=150$. The model is based on a real device [4].

If all four transistors (fig. 1 (a)) were held at $25^{\circ} \mathrm{C}$ the output current was found to be $\mathrm{I}_{\text {out }}=500 \mu \mathrm{A}$ for an output voltage $V_{\text {out }}=4.7 \mathrm{~V}$ or a relative deviation $\left|\mathrm{I}_{\text {out }}-\mathrm{I}_{\text {in }}\right| / \mathrm{I}_{\text {in }}=0 \%$. By varying the output voltage, the output resistance $R_{\text {out }}$ could be determined. One got $R_{\text {out }}=7 \mathrm{M} \Omega$. Heating up any single transistor to $35^{\circ} \mathrm{C}$ at a time led to no significant current error $\left|\mathrm{I}_{\text {out }}-\mathrm{I}_{\text {in }}\right| / \mathrm{I}_{\text {in }}<0.03 \%$ when applied to transistor 3 or 4 . Only when either transistors 1 or 2 were heated up the output current error would become significant (2.3\% and $2.4 \%$ respectively). Hence one came to the conclusion that a temperature variation of one of the two bottom transistors $\left(T_{1}, T_{2}\right)$ has a much more pronounced influence on the behaviour of the current mirror. It should be noted that influence on the output resistance was limited ranging from $6.77 \mathrm{M} \Omega$ to $7.25 \mathrm{M} \Omega$.

Similar results have been found for other values of the input current $\mathrm{I}_{\text {in }}$. At higher temperatures (one transistor at $85^{\circ} \mathrm{C}$, the other at $75^{\circ} \mathrm{C}$ ) the same conclusions still hold.

It should be noted here that the results are proportional to the temperature difference. For a temperature difference of only $1^{\circ} \mathrm{C}$ instead of $10^{\circ} \mathrm{C}$ the above mentioned values for $\left|I_{\text {out }}-I_{\text {in }}\right| / I_{\text {in }}$ have to be 10 times smaller. Moreover when dealing with a thermal gradient it is assumed that the self heating of the transistors has a negligible influence on the temperature distribution.

If the current mirror is under the thermal influence of other components integrated in the same chip, it is quite obvious to approximate the spatial temperature distribution as a superposition of a uniform temperature rise and a thermal gradient field. It is also assumed that the four transistors are located on the corners of a square. Some results obtained with temperature gradients in 8 different directions are shown in table 1.

The first result is that the output resistance of a cascode mirror is not significantly affected by temperature distribution. The influence on the output current however is much more pronounced. Only the case 1 and 5, where the transistors on the left have the same temperature as the transistors on the right, the output current equals the input one. This result is quite obvious, because the circuit remains symmetrical under the influence of a temperature gradient oriented 
vertically. For all other cases, the relative error is in the range of a few percent.

\section{NUMERICAL SIMULATION OF THE QUAD LAYOUT}

The idea of the quad layout originates from one of the first designs of the input stage of an operational amplifier [6]. Each of the two transistors 1 and 2 in fig.1(a) is replaced by two equal transistors in parallel: 1-1' and 2-2' giving rise to the new circuit shown in fig.1(b).

The four transistors 1, 1', 2 and 2' must be placed on the corners of a square as depicted in fig.1(b) as well. Whatever the orientation of the thermal gradient might be, a "colder" transistor is always connected in parallel with a "warmer" one so that the difference in their characteristics will be compensated.

The transistors 3 and 4 were not replaced by equivalent parallel combinations as it was clearly demonstrated their temperature mismatch has a minor influence on current mirror performance. During the simulations, $\mathrm{T}_{3}=\mathrm{T}_{4}=25^{\circ} \mathrm{C}$ was used for simplicity.

The simulation results are shown in table 2. First of all, one observes that the output resistance is almost the same as for the cascode mirror. The error $\left|I_{\text {out }}-I_{\text {in }}\right| / I_{\text {in }}$ is now two orders of magnitude less which can be regarded as a considerable improvement. This circuit can be considered as insensitive to any temperature gradient. The price one has to pay is that the layout is a bit more complicated ( 4 bottom transistors instead of 2 and more interconnections).

\section{ANALyTiCAL MODEL}

In this section it will be proved theoretically that the transistors 3 and 4 of the typical cascode mirror (fig.1(a)) have a minor influence on the error $\left|I_{\text {out }}-I_{\text {in }}\right| / I_{\text {in }}$ compared to the bottom transistors 1 and 2 .

An incremental model of the cascode current mirror of fig.1(a) is drawn in fig.2. A MOS transistor is represented by a transconductance $g_{m}$ and an output resistance $r_{0}$ [7]. In order to take into account the temperature effects, (incremental) voltages $-\alpha \Delta T$ have to be added to the gate voltages $\Delta \mathrm{V}_{\mathrm{G}}$ in order to provide the drain current $g_{m}\left(\Delta \mathrm{V}_{\mathrm{G}}-\alpha \Delta \mathrm{T}\right)$.

Without going into the mathematical details, the final result is found to be:

$$
\Delta V_{\text {out }}=r_{0}\left(2+g_{m} r_{0}\right) \Delta I_{\text {out }}+\frac{g_{m}^{2} r_{0}^{2} \alpha}{1+g_{m} r_{0}}\left[\left(1+g_{m} r_{0}\right) \Delta T_{1}+\Delta T_{3}\right]-g_{m} r_{0} \alpha\left[\left(1+g_{m} r_{0}\right) \Delta T_{2}+\Delta T_{4}\right]
$$

For a MOS transistor $g_{m} r_{0}>>1$ so that (1) can be simplified to:

$$
\Delta \mathrm{V}_{\text {out }}=\mathrm{g}_{\mathrm{m}} \mathrm{r}_{0}^{2} \Delta \mathrm{I}_{\text {out }}+\mathrm{g}_{\mathrm{m}}^{2} \mathrm{r}_{0}^{2} \alpha\left[\Delta \mathrm{T}_{1}-\Delta \mathrm{T}_{2}\right]-\mathrm{g}_{\mathrm{m}} \mathrm{r}_{0} \alpha\left[\Delta \mathrm{T}_{3}-\Delta \mathrm{T}_{4}\right]
$$


The first term of (1) and (2) gives the output resistance $\mathrm{R}_{\text {out }}$ of the current mirror:

$$
\mathrm{R}_{\text {out }}=\mathrm{r}_{0}\left(2+\mathrm{gm}_{\mathrm{m}} \mathrm{r}_{0}\right) \approx \mathrm{gm}_{\mathrm{m}} \mathrm{r}_{0}^{2}
$$

The other terms provide the influence of the temperature. Obviously if

$$
\Delta T_{1}=\Delta T_{2}=\Delta T_{3}=\Delta T_{4}
$$

, it is proved by (2) that there is no influence on the output current. Even when

$$
\Delta T_{1}=\Delta T_{2} \neq \Delta T_{3}=\Delta T_{4}
$$

the output current is not influenced. From (2) it is also clear that the coefficient of $\Delta \mathrm{T}_{1}-\Delta \mathrm{T}_{2}$ is much greater than the coefficient of $\Delta T_{3}-\Delta T_{4}$ which proves that a temperature variation of the bottom transistors has a major influence on the overall behaviour of the current mirror. This result agrees with the numerical simulation outline above.

In case of the quad configuration fig.1(b) each transistor 1 and 2 was replaced by a parallel connection 1-1' and 2-2'. These transistors having the half width of the original one, so that their transconductance is $g_{m} / 2$, their output resistance $2 R_{0}$ and the temperature dependence is $\alpha / 2$. The second term of the right hand member of (2) becomes now:

$$
\frac{1}{2} \mathrm{~g}_{\mathrm{m}}^{2} \mathrm{r}_{0}^{2} \alpha\left[\Delta \mathrm{T}_{1}+\Delta \mathrm{T}_{1^{\prime}}-\Delta \mathrm{T}_{2}-\Delta \mathrm{T}_{2^{\prime}}\right]
$$

Due to the fact that the four transistors 1, 1', 2 and 2' are located on the corners of a square (fig.1(b)), one has:

$$
\Delta T_{1}+\Delta T_{1^{\prime}}-\Delta T_{2}-\Delta T_{2^{\prime}}=0
$$

for any possible direction of the thermal gradient. This explains why the quad configuration is much less sensitive to the thermal gradient as compared to the classical cascode layout of fig. $1(\mathrm{a})$.

\section{CONCLUSION}

The influence of a temperature gradient on a cascode current mirror has been analysed. A possible solution based on the quad layout of the two bottom transistors turned out to be almost insensitive to any temperature gradient. The results were obtained using numerical simulations (SPICE) and analytical calculations. 


\section{ACKNOWLEDGMENT}

This research was initiated within Erasmus exchange programme participation of M. Jablonski who currently pursues a PhD degree at the Ghent University.

\section{REFERENCES}

[1] Tenbroek, B. M.: "Drain current mismatch in SOI CMOS current mirrors and D/A converters due to localised internal and couped heating," proc. European Solid-State Circuits Conf.(ESSCIRC), 1997, pp. 276-278,

[2] Baker, R.: "CMOS : circuit design, layout, and simulation, Vol. 1", Wiley-IEEE, 2nd edition, 2008.

[3] Gray, P., Hurst P., Lewis S., and Meyer, R.: "Analysis and design of analog integrated circuits", Wiley, New York, 2001, p.331-332.

[4] Zeki, A. and Kuntuman, H.: "Accurate active feedback CMOS cascode current mirror with improved output swing"', Int. J. of Electronics, 1998, vol.84, p.335-343.

[5] Texas instruments: "TINA, Spice based circuit simulator", ver. 7.0.8, http://focus.t1.com/docs/toolsw/folders/print/tina-ti.html

[6] Solomon, J.: "The monolithic OPAMP: a tutorial study", IEEE Journal on Solid State Circuits, 1974, vol.SC-9; p.314-332.

[7] Floyd, T. and Buchla, D.: "Fundamentals of analog circuits"', Prentice Hall, New Jersey, 1999, p.228-230. 


\section{Authors affiliations}

Michał Jabłoński

(CMST, Department ELIS, Ghent University/IMEC, Technologiepark 914a, 9052 Ghent, Belgium) Email: michal.jablonski@elis.ugent.be

Gilbert De Mey

(Department ELIS, Ghent University, Sint Pietersnieuwstraat 419000 Ghent, Belgium )

Andrzej Kos

(Institute of Electronics, AGH University of Science and Technology, Mickiewicza 30, 30-059 Kraków, Poland) 


\section{LIST OF TABLES}

Table I: Influence of temperature gradient on the performance of the cascode current mirror Table II: Influence of temperature gradient on the performance of the cascode current mirror with quad layout for the bottom transistors 
TABLE I

\begin{tabular}{|c|c|c|c|c|c|}
\hline \multirow[b]{2}{*}{ case } & & \multirow{2}{*}{$\begin{array}{l}\mathrm{T}_{3} \\
\mathrm{~T}_{1} \\
\end{array}$} & \multirow{2}{*}{$\begin{array}{l}\mathrm{T}_{4} \\
\mathrm{~T}_{2}\end{array}$} & \multicolumn{2}{|c|}{ cascode mirror } \\
\hline & & & & $\left|I_{\text {out }}-I_{\text {in }}\right| / I_{\text {in }}$ & $R_{\text {out }} M \Omega$ \\
\hline \multirow[b]{2}{*}{0} & & 25 & 25 & \multirow[b]{2}{*}{$0.00 \%$} & \multirow[b]{2}{*}{6.99} \\
\hline & & 25 & 25 & & \\
\hline \multirow[b]{2}{*}{1} & \multirow[b]{2}{*}{$\uparrow$} & 35 & 35 & \multirow[b]{2}{*}{$<0.01 \%$} & \multirow[b]{2}{*}{6.82} \\
\hline & & 25 & 25 & & \\
\hline \multirow[b]{2}{*}{2} & \multirow[b]{2}{*}{$\nearrow$} & 30 & 35 & \multirow[b]{2}{*}{$1.21 \%$} & \multirow[b]{2}{*}{6.94} \\
\hline & & 25 & 30 & & \\
\hline \multirow[b]{2}{*}{3} & \multirow[b]{2}{*}{$\rightarrow$} & 25 & 35 & \multirow[b]{2}{*}{$2.37 \%$} & \multirow[b]{2}{*}{7.07} \\
\hline & & 25 & 35 & & \\
\hline \multirow[b]{2}{*}{4} & \multirow[b]{2}{*}{$\searrow$} & 25 & 30 & \multirow[b]{2}{*}{$1.18 \%$} & \multirow[b]{2}{*}{7.03} \\
\hline & & 30 & 35 & & \\
\hline \multirow[b]{2}{*}{5} & \multirow[b]{2}{*}{$\downarrow$} & 25 & 25 & \multirow[b]{2}{*}{$<0.01 \%$} & \multirow[b]{2}{*}{6.99} \\
\hline & & 35 & 35 & & \\
\hline \multirow[b]{2}{*}{6} & \multirow[b]{2}{*}{$\swarrow$} & 30 & 25 & \multirow[b]{2}{*}{$1.20 \%$} & \multirow[b]{2}{*}{6.87} \\
\hline & & 35 & 30 & & \\
\hline \multirow[b]{2}{*}{7} & \multirow[b]{2}{*}{$\leftarrow$} & 35 & 25 & \multirow[b]{2}{*}{$2.45 \%$} & \multirow[b]{2}{*}{6.74} \\
\hline & & 35 & 25 & & \\
\hline \multirow[b]{2}{*}{8} & & 35 & 30 & & \\
\hline & $\nwarrow$ & 30 & 25 & $1.23 \%$ & 6.78 \\
\hline
\end{tabular}


TABLE II

\begin{tabular}{|c|c|c|c|c|c|}
\hline \multirow[b]{2}{*}{ case } & & \multirow{2}{*}{$\begin{array}{l}\mathrm{T}_{1} \\
\mathrm{~T}_{2}^{\prime} \\
\end{array}$} & \multirow{2}{*}{$\begin{array}{l}\mathrm{T}_{2} \\
\mathrm{~T}_{1}^{\prime}\end{array}$} & \multicolumn{2}{|c|}{ quad cascode mirror } \\
\hline & & & & $\left|I_{\text {out }}-I_{\text {in }}\right| / I_{\text {in }}$ & $\mathrm{R}_{\text {out }} \mathrm{M} \Omega$ \\
\hline \multirow[b]{2}{*}{0} & & 25 & 25 & \multirow[b]{2}{*}{$0.00 \%$} & \multirow[b]{2}{*}{7.012} \\
\hline & & 25 & 25 & & \\
\hline \multirow[b]{2}{*}{1} & \multirow[b]{2}{*}{$\uparrow$} & 35 & 35 & \multirow[b]{2}{*}{$<0.01 \%$} & \multirow[b]{2}{*}{7.011} \\
\hline & & 25 & 25 & & \\
\hline \multirow[b]{2}{*}{2} & \multirow[b]{2}{*}{$\nearrow$} & 30 & 35 & \multirow[b]{2}{*}{$0.03 \%$} & \multirow[b]{2}{*}{7.008} \\
\hline & & 25 & 30 & & \\
\hline \multirow[b]{2}{*}{3} & \multirow[b]{2}{*}{$\rightarrow$} & 25 & 35 & \multirow[b]{2}{*}{$<0.01 \%$} & \multirow[b]{2}{*}{7.011} \\
\hline & & 25 & 35 & & \\
\hline \multirow[b]{2}{*}{4} & \multirow[b]{2}{*}{$\searrow$} & 25 & 30 & \multirow[b]{2}{*}{$0.03 \%$} & \multirow[b]{2}{*}{7.014} \\
\hline & & 30 & 35 & & \\
\hline \multirow[b]{2}{*}{5} & \multirow[b]{2}{*}{$\downarrow$} & 25 & 25 & \multirow[b]{2}{*}{$<0.01 \%$} & \multirow[b]{2}{*}{7.011} \\
\hline & & 35 & 35 & & \\
\hline \multirow[b]{2}{*}{6} & \multirow[b]{2}{*}{$\swarrow$} & 30 & 25 & \multirow[b]{2}{*}{$0.03 \%$} & \multirow[b]{2}{*}{7.008} \\
\hline & & 35 & 30 & & \\
\hline \multirow[b]{2}{*}{7} & \multirow[b]{2}{*}{$\leftarrow$} & 35 & 25 & \multirow[b]{2}{*}{$<0.01 \%$} & \multirow[b]{2}{*}{7.011} \\
\hline & & 35 & 25 & & \\
\hline \multirow[b]{2}{*}{8} & & 35 & 30 & & \\
\hline & $\nwarrow$ & 30 & 25 & $0.03 \%$ & 7.014 \\
\hline
\end{tabular}


LIST OF FIGURES

Fig. 1: Basic (a) and quad (b) cascode current mirror circuits

Fig. 2: Equivalent incremental network of the cascode current mirror 


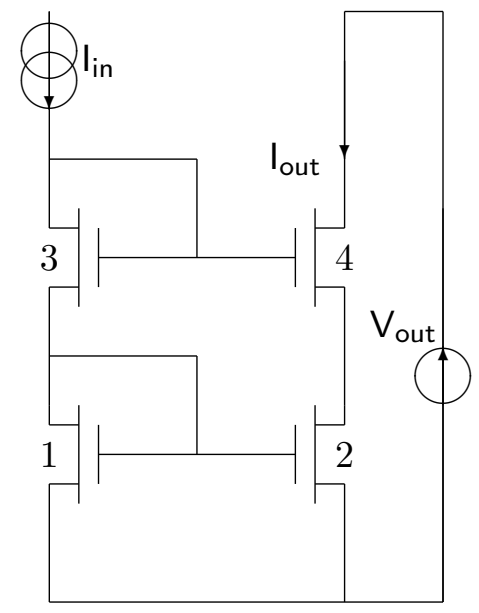

(a)

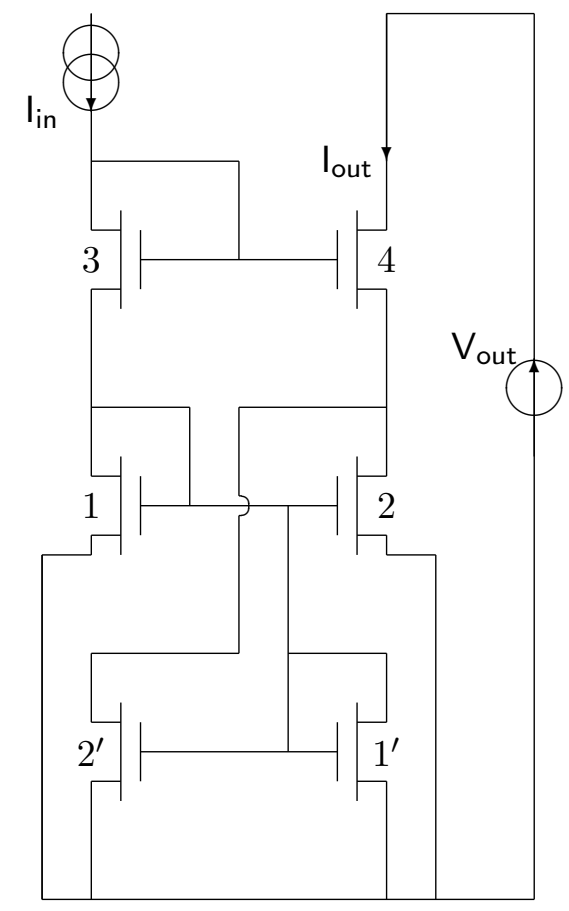

(b)

Fig. 1. 


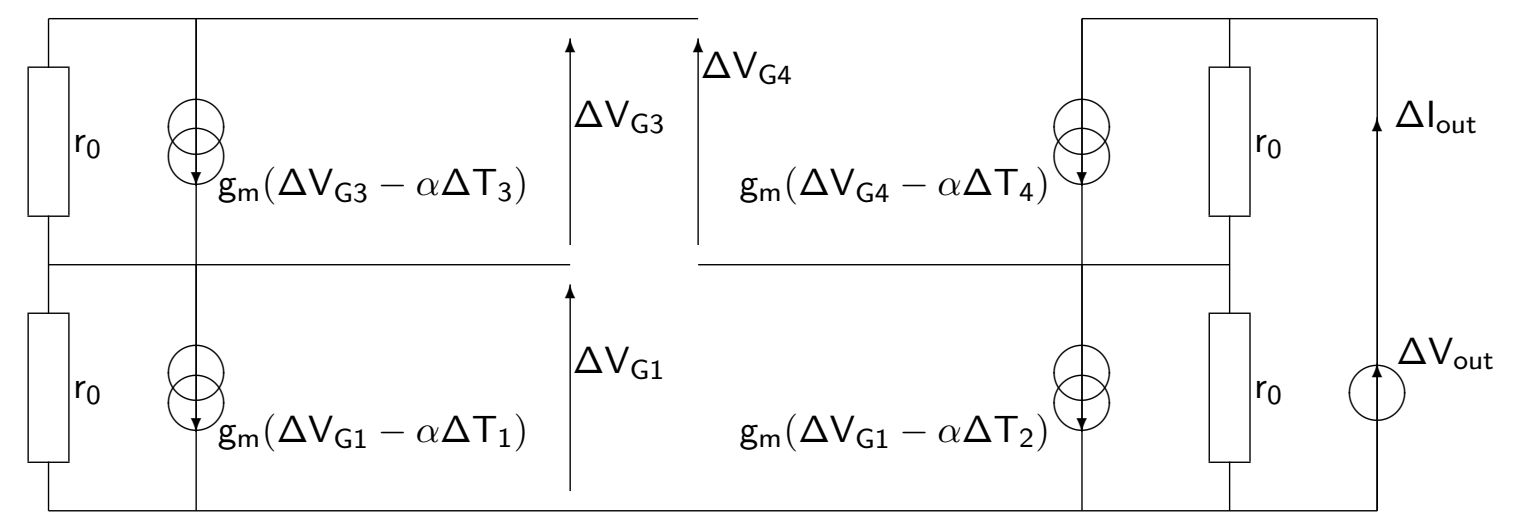

Fig. 2. 